\title{
Recorregut de recerca geològica i mineralògica per la comarca del Baix Camp: des de la Mussara a la Febró i a Prades
}

Josep Maria Mata-Perelló

Joaquim Sanz Balagué

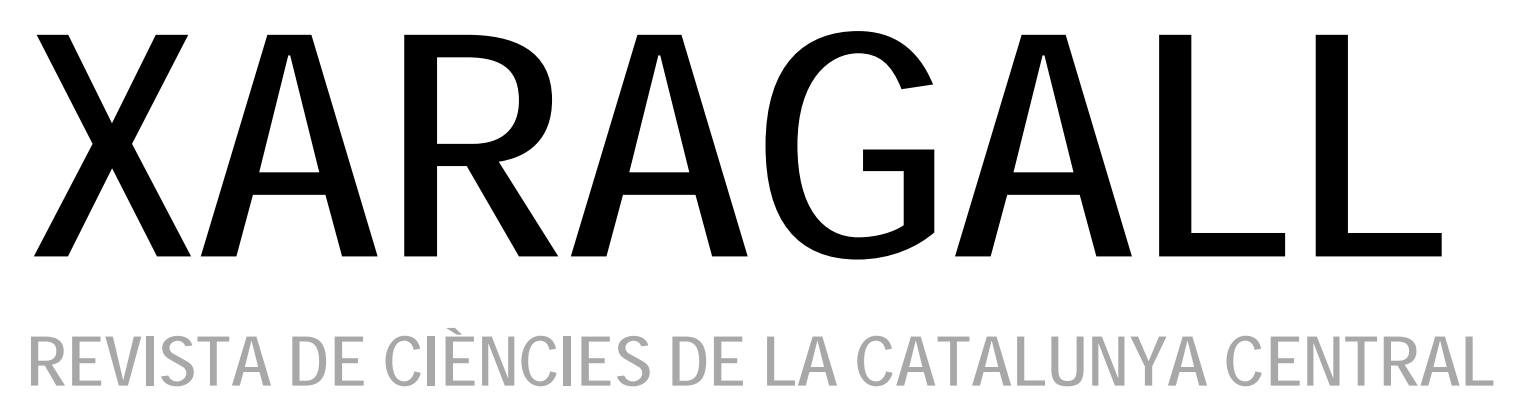

n. 4

ABRIL 2015 


\title{
RECORREGUT DE RECERCA GEOLÒGICA I MINERALÒGICA PER LA COMARCA DEL BAIX CAMP: DES DE LA MUSSARA A LA FEBRÓ I A PRADES
}

\author{
Josep Maria Mata-Perelló \\ Museu de geologia Valentí Masachs, Escola Politècnica Superior d'Enginyeria de Manresa \\ (EPSEM), Universitat Politècnica de Catalunya · BarcelonaTech (UPC), 08272 Manresa, Spain
}

\section{Joaquim Sanz Balagué}

Departament d'Enginyeria Minera i Recursos Naturals (EMRN), Escola Politècnica Superior d'Enginyeria de Manresa (EPSEM), Universitat Politècnica de Catalunya . BarcelonaTech (UPC), 08272 Manresa, Spain

Paraules clau: Sistema Mediterrani, Materials mesozoics, Materials paleozoics, Patrimoni miner

\section{Resum}

Itinerari realitzat el 24 de maig de 2014. En aquesta ocasió, el recorregut de l'itinerari discorrerà íntegrament pel sistema Mediterrani (i més concretament per la seva sots-unitat més interna: per la Serralada Prelitoral Catalana). Així, discorrerà pràcticament entre la Mussara, la Febró i la població de Prades, prop d’on finalitzarà.

Així doncs, la totalitat del recorregut de l'itinerari, es realitzarà per la Serralada Prelitoral Catalana, entre els afloraments dels materials paleozoics i els mesozoics que la constitueixen, per aquests indrets.

Per altra banda, la totalitat del recorregut es realitzarà totalment per dintre de la comarca del Baix Camp, des la localitat de la Mussara fins arribar a la població de Prades. 


\section{Objectius fonamentals}

Els objectius fonamentals que es pretenen aconseguir en aquest itinerari, es poden concretar en els següents aspectes generals:

1. Estudi i observació de la Serralada Prelitoral Catalana (integrada dintre del Sistema Mediterrani), per la qual discorrerà el recorregut de l'itinerari en quasi tot el seu recorregut, entre la Mussara, la Febró i Prades.

2. Reconeixement dels materials paleozoics (del Carbonífer), i dels mesozoics (del Triàsic). que constitueixen la Serralada Prelitoral Catalana, els quals tallarem entre els indrets abans esmentats. Així, els carbonífers, els tindrem presents al llarg del recorregut de tot l'itinerari.

3. Visió de diferents mineralitzacions, que es vagin trobant sal llarg del recorregut del present itinerari

4. Observació de les diferents explotacions mineres que anirem trobant al llarg del recorregut. I alhora, observació, si s'escau, de les tasques de restauració dutes a terme a les explotacions anteriors.

5. Observació de diferents indrets del Patrimoni Geològic i Miner, situats al llarg del recorregut. Entre aquests elements, cal parlar del paratge dels Avencs de la Fredó; entre molts altres indrets del recorregut de l'itinerari.

\section{Antecedents}

Pel que fa al recorregut del present itinerari, existeixen diversos antecedents nostres, de tipus bibliogràfic referent a diferents indrets del recorregut de l'itinerari. Es tracta de MATAPERELLÓ i COLLDEFORNS (1994); així com els de MATA-PERELLÓ (1996, 1998, 2004, 2005 i 2012).

Pel que fa a la descripció de les mineralitzacions d'aquesta comarca, cal parlar dels treballs de MATA-PERELLÓ (1991), relatiu a les mineralitzacions catalanes en general; i també dels de MELGAREJO (1992), centrat en els materials i les mineralitzacions del paleozoic, de les comarques del Baix Camp, de la Conca de Barberà i del Priorat

Per altra banda, i pel que fa a les característiques dels materials geològics que anirem tallant, ens referirem als treballs de COLOMBO (1986 i 1989). I pel que fa a l'estructura geològica farem esment de dos treballs; de: GUIMERÀ et altri (1982) i de RIBA et altri (1976).

Tots aquests treballs referenciats, i d'altres, figuren esmentats per ordre alfabètic a l'apartat dedicat a la BIBLIOGRAFIA. 


\section{Recorregut de l'itinerari}

Tot i que el recorregut s'iniciarà al despoblat de la Mussara, per on es farà la primera aturada del recorregut d'aquest itinerari. I, tot seguit, caldrà dirigir-se cap a la població de la Febró, tot seguint la carretera local T - 704. En aquest recorregut es faran diverses aturades.

Posteriorment, per la mateixa carretera, s'arribarà fins a la població de Prades, per on s' efectuaran diverses aturades. La darrera es farà al Turó de la Baltasana, on s'arribarà des de la carretera $T-700$, la qual s' haurà agafat a Prades. En aquest turó, finalitzarà aquest itinerari.

\section{Advertiments previs}

Com en altres recorreguts de RECERCA GEOLÒGICA I MINERALÒGICA ..., si es disposa del temps suficient, poden efectuar-se passant per totes les parades i filloles. En cas contrari, recomanem reestructurar el recorregut, prescindint de les anomenades PARADES CONDICIONALS, i d'altres si s'escau.

També recomanem de cercar la informació més adient, sobre els trams a recórrer mitjançant camins de terra, o de pista.

Per altra banda, recomanem tenir una cura extrema de la NATURA, evitant qualsevol forma d'agressió sobre ella, o de fer-n'hi un mal ús del que en ofereix la nostra mare Terra.

\section{Descripció de l'itinerari}

Tot i que el recorregut s'iniciarà al despoblat de la Mussara, per on es farà la primera aturada del recorregut d'aquest itinerari. I, tot seguit, caldrà dirigir-se cap a la població de la Febró, tot seguint la carretera local T - 704. En aquest recorregut es faran diverses aturades.

Posteriorment, per la mateixa carretera, s'arribarà fins a la població de Prades, per on s' efectuaran diverses aturades. La darrera es farà al Turó de la Baltasana, on s'arribarà des de la carretera $T-700$, la qual s' haurà agafat a Prades. En aquest turó, finalitzarà aquest itinerari.

\subsection{Parada 1. MIRADOR DE LA MUSSARA, (antic terme de la Mussara, actual de Vilaplana del Camp, comarca del Baix Camp). (Full 445).}

Aquest itinerari el començarem en aquest indret. Aquí s'hi pot arribar des d'Alforja i del Coll d'Alforja, seguint primer la carretera comarcal C - 242, després la carretera local TV-7092 i finalment la local T-704. Per aquest recorregut caldrà fer uns $22^{\prime} 5 \mathrm{Km}$, aproximadament.

També es pot arribar des de la població de Vilaplana, utilitzant la carretera local T - 704. En aquest cas, el recorregut haurà estat poc més de 21'5.

En qualsevol cas, s'arriba fins a la cruilla d'on eix la carretereta que condueix directament cap ala Mussara, la TV-7093. En arribar-hi, i després de recórrer menys de 1 Km, des de la cruïlla cal fer la present. 
En aquest trajecte, hem transitat pel contacte entre els nivells carbonatats del Muschelkalk Superior, amb els lutítics i guixosos del Keuper. I, ara ens trobem, precisament sobre aquest mateix contacte. De forma que la Mussara es troba sobre la cuesta que formen els materials carbonatats, i estenent-se més amunt els del Keuper.

Des d'aquest lloc, es pot gaudir d'un immillorable punt d'observació de la Serralada Prelitoral, (on estem situats), i també de la Depressió Prelitoral (Depressió del Camp), la qual s'estén amplament cap al Sud, d'on ara ens trobem situats. (fotografia 1).

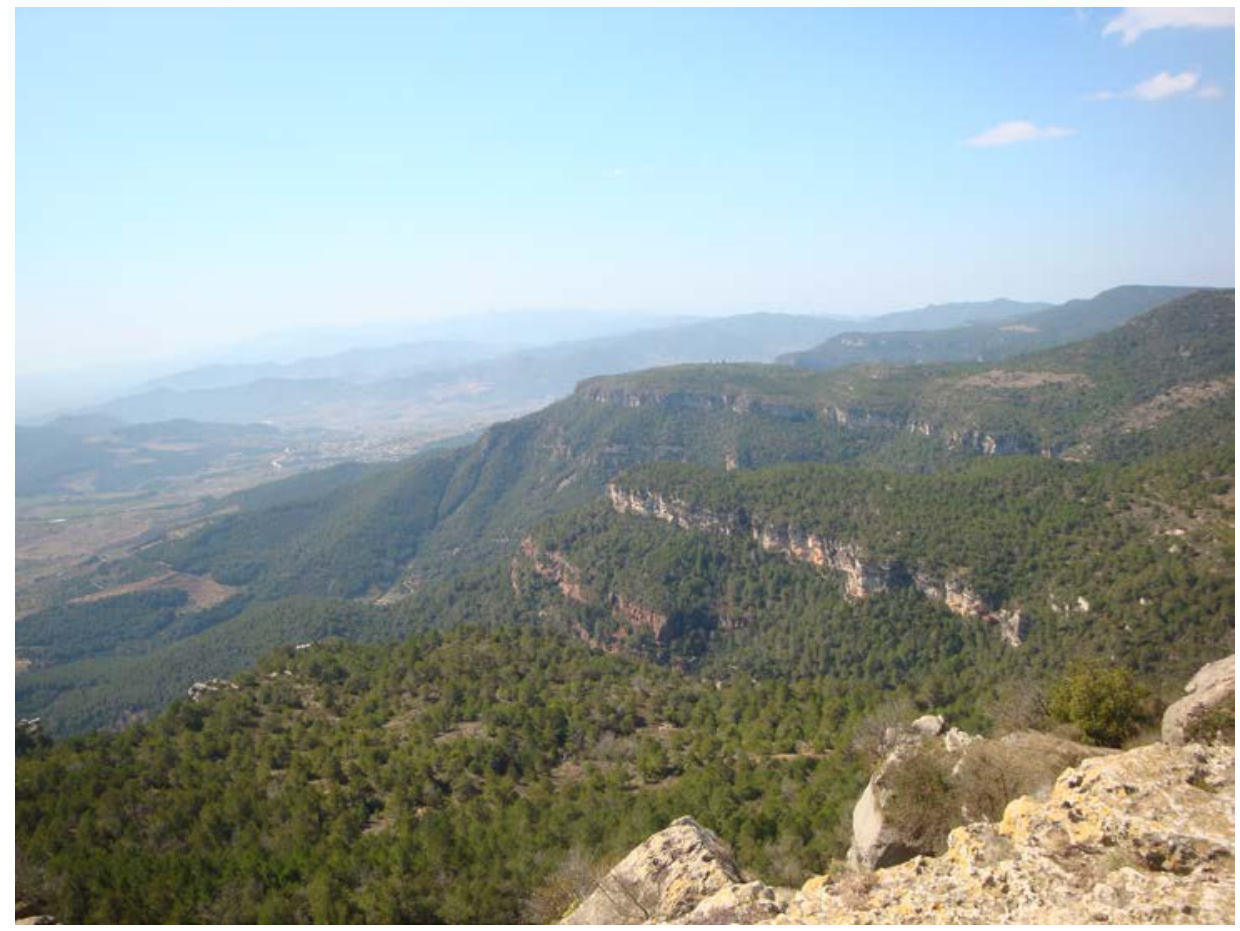

Fotografia 1. Aflorament dels nivells carbonatats del Muschelkalk Superior (en primer terme). Per sota es veu la zona on afloren els nivells rogencs del Muschelkalk Mig Per sota es veuen els nivells carbonatats del Muschelkalk Inferior. Tanmateix, per sota d'aquests es veuen els gresos del Buntsandstein I per sota els nivells del Carbonífer 


\subsection{Parada 2. ELS AVENCS DE LA FEBRÓ, (terme municipal de la Febró, comarca del Baix Camp). (Full 445).}

Des de la parada anterior, cal retrocedir des de la Mussara, fins a trobar la carretera procedent de Vilaplana (la T - 704). En trobar-la, ens caldrà anar cap a ponent. Tot i així, ben prop del camí trobarem un camí que ens conduirà fins un collet, des del qual surt un corriol que va als Avencs de la Febró. En arribar-hi, a uns $5 \mathrm{Km}$ de la parada anterior, n'efectuarem una altra. Així, des de la carretera, haurem recorregut poc més de $1^{\prime} 5 \mathrm{Km}$. I tanmateix uns 400 metres a peu.

En aquest recorregut, en sortir de la carretera, haurem trobat uns afloraments dels nivells de calcàries del Muschelkalk Superior. Després, per sobre d'aquests haurem trobat uns nivells argilosos, calcolutítics i guixosos, que pertanyen al Keuper, al tram superior del Triàsic). Després, per sobre d'aquests, a l'indret on ara som, haureu trobat afloraments dels nivells carbonatats del Juràssic. Aquests materials es troben enormement fracturats, com succeeix a l'indret de l'aturada.

Per altra banda, en aquest lloc es poden veure les enormes esquerdes que tallen als materials carbonatats del Juràssic. Es definitiva, es tracta d'un nivell competent, situat entre els nivells tous del Muschelkalk Mig. Així, s'han originat unes espectaculars diàclasis - esquerdes, que tallen als materials carbonatats anteriorment esmentats. (fotografies 2,3 i 4).

Sobre aquestes esquerdes, s'han generat fenòmens associats a kartstificació, que han donat lloc a un conjunt de coves.

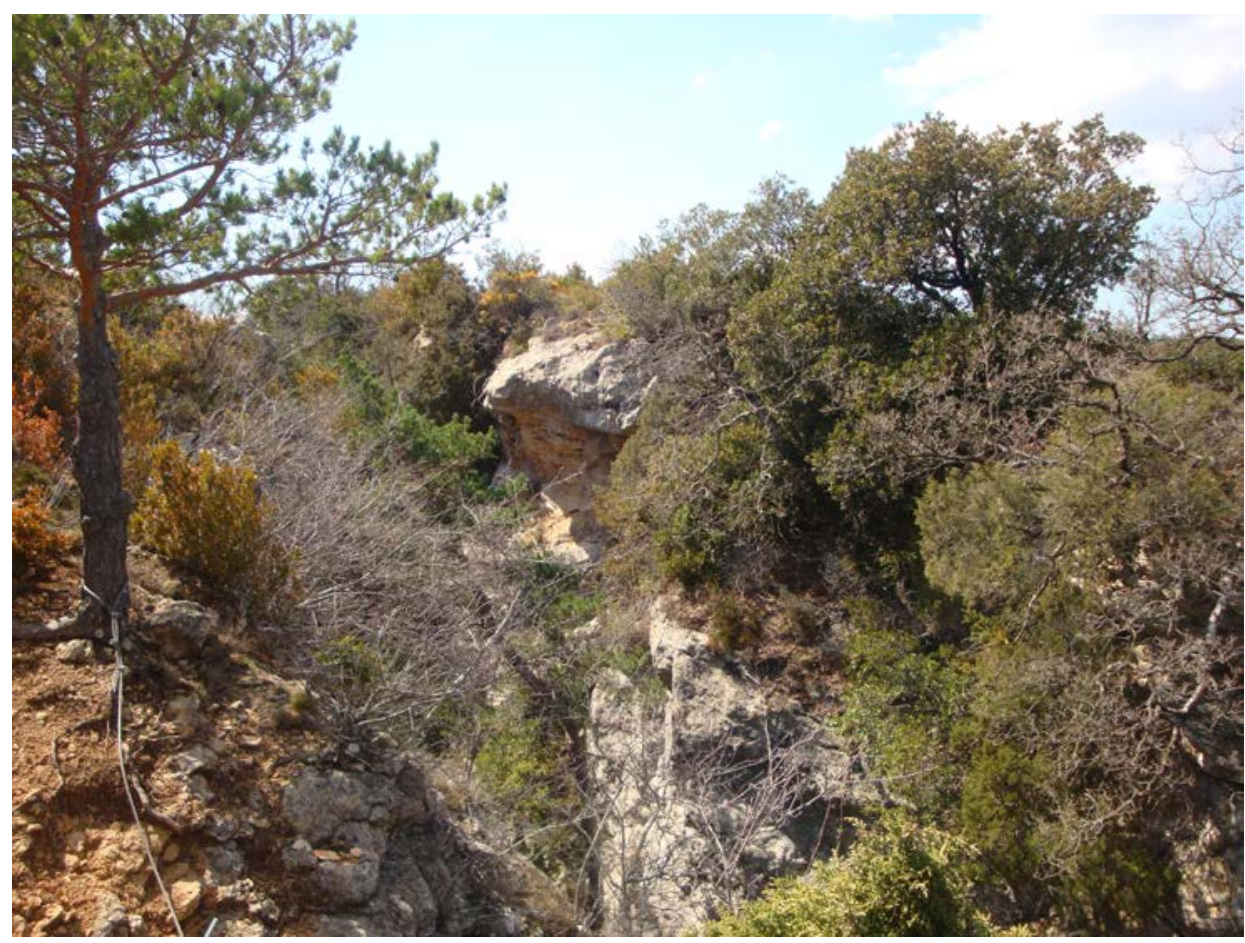

Fotografia 2. Un aspecte de les esquerdes 

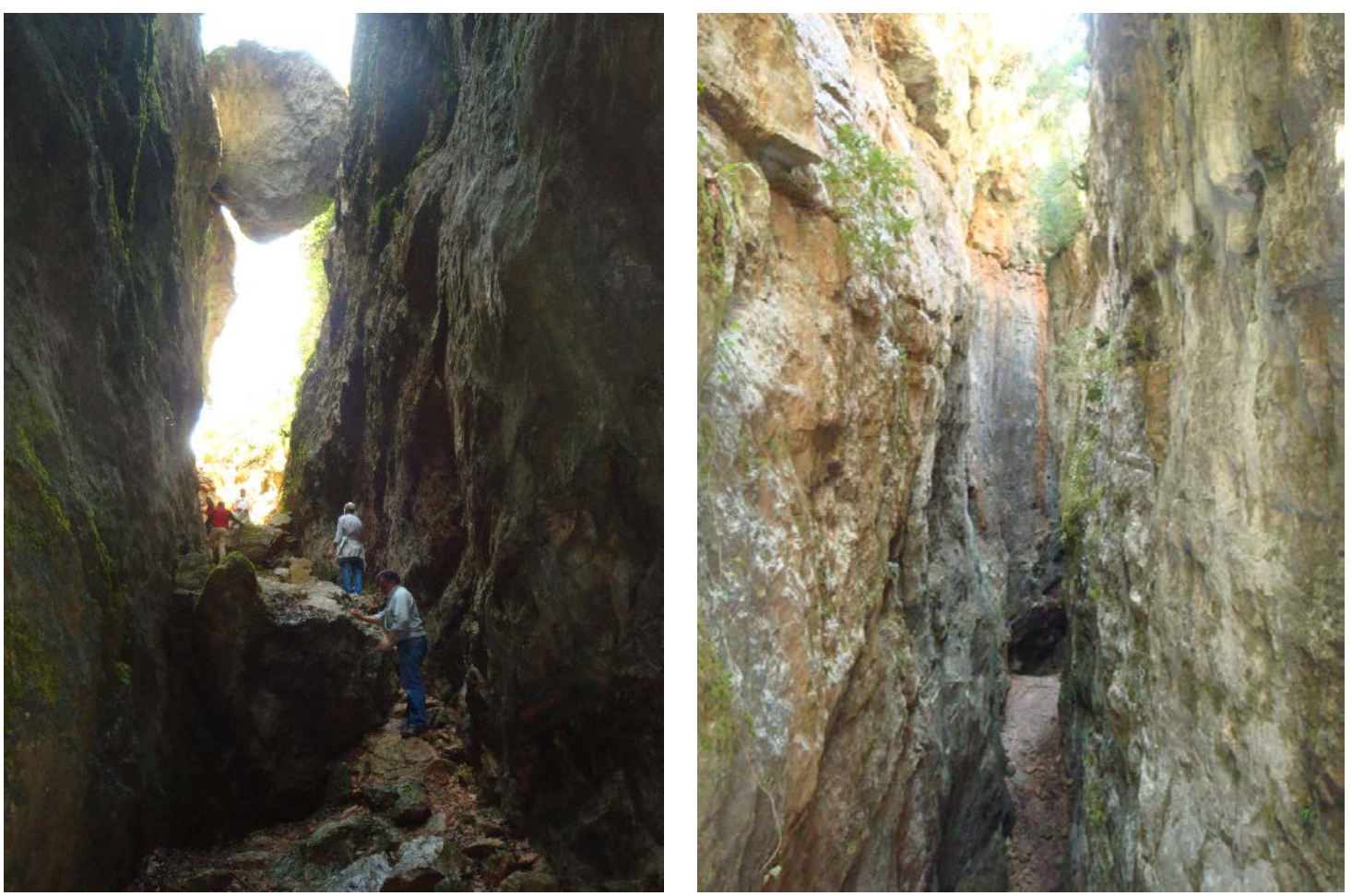

Fotografies 3 i 4 . Dos aspectes de la part baixa dels Avencs de la Febró

\subsection{Parada 3. MAS DELS FRARES, (terme de la Febró, comarca del Baix Camp). (Full 445).}

Des de la parada anterior, cal retornar cap a la carretera T-704 (la qual uneix Reus amb Prades), per tal de tornar enrere, i de continuar cap a la Febró. A uns $3 \mathrm{Km}$ abans d'arribar a la Febró, pels voltants del Mas dels Frares, cal fer la present aturada, a uns 6’ $5 \mathrm{Km}$ de l'anterior.

En aquest recorregut, hem anat tallant els materials mesozoics que constitueixen la Serralada Prelitoral Catalana. Així, bona part del recorregut s'efectua per entre els nivells lutítics i guixosos del Keuper (Triàsic Superior), trobant-se per sota els nivells carbonatats del Muschelkalk Superior (Triàsic Mig), i per dalt els nivells carbonatats del Liàsic (Juràssic Inferior). Per d'altra banda, cal dir que al indret de la parada, es troben els materials del Keuper abans esmentats. (fotografía 5). 


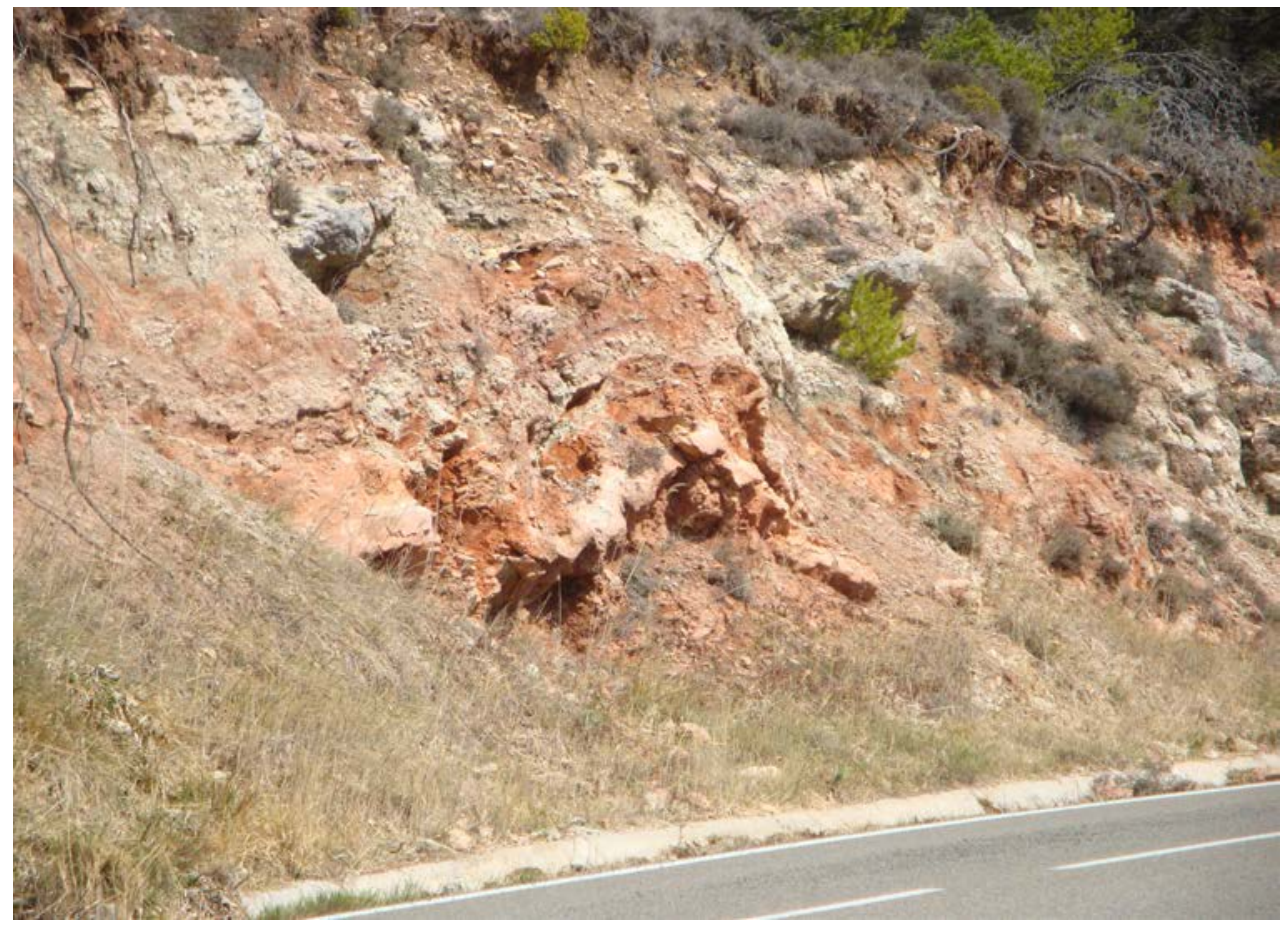

Fotografia 5. Afloraments de les calcolutites i guixos del Muschelkalk Mig

Des d'aquest indret, es pot trobar un bon punt d'observació (a l'esquerra del sentit de la carretera) dels engorjats del Riu Siurana, el qual discorre encaixonat entre els materials carbonatats del Muschelkalk Superior. Així, es pot veure com l'esmentat riu discorre tot seguint una fractura que afecta als materials carbonatats acabats d'esmentar.

\subsection{Parada 4. LA PORTA DE PRADES, (terme municipal de Prades, comarca del Baix Camp). (Full 445).}

Després de la parada anterior, cal continuar cap a la Febró i cap a Prades, tot seguint sempre la carretera local T-704. En arribar a l'entrada del darrer poble, cal fer la present aturada, després de recórrer uns $9 \mathrm{Km}$, des de l'anterior.

En el recorregut es continuen tallant els materials del Keuper, en un principi. Però poc abans d'arribar al Coll de Capafonts, es sobrepassa una falla que posa en contacte els materials anteriors amb els del Muschelkalk Superior. I, des d'enllà fins a Prades, es fa un tall descendent dels materials de la resta del Muschelkalk, i també dels del Buntsandstein. Així, en arribar a la vila de Prades, es troben bons afloraments del nivells rogencs del Buntsandstein, constituïts per gresos i lutites.

Precisament, els primers s'han utilitzat per a la construcció de l'església parroquial, i la porta de les muralles, com es pot observar en aquesta aturada urbana. (fotografía 6). 


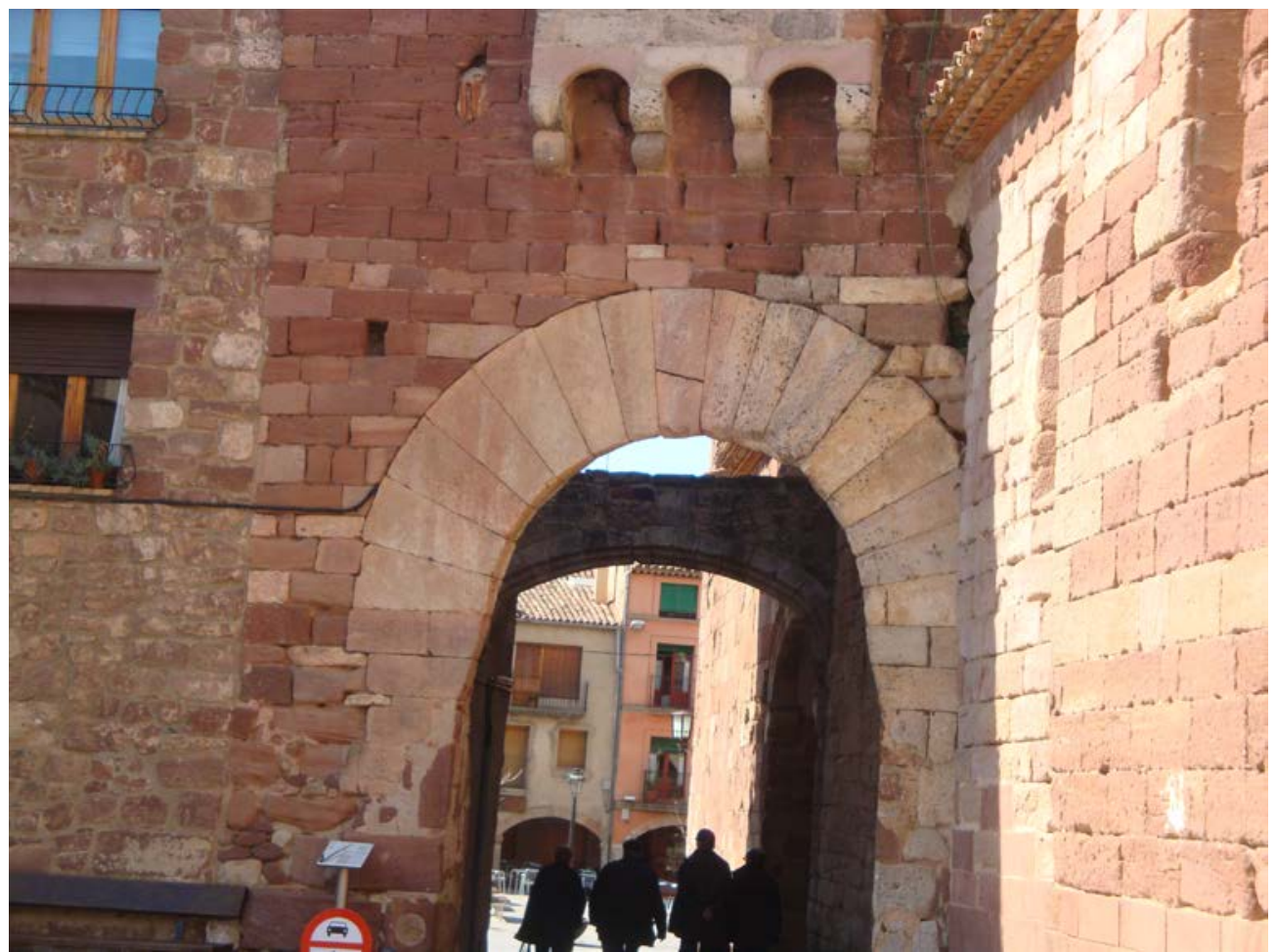

Fotografia 6. Porta de Prades i façana de l'església, amb carreus dels materials del Buntsandstein. Dintre de la plaça, es poden veure diversos edificis, amb característiques semblants als de la façana de l'Església

\subsection{Parada 5. MINA DEL TOSSAL DE LA BALTASANA, (terme municipal de Prades, comarca del Baix Camp). (Full 445).}

Des de la parada anterior, cal seguir per la carretera $\mathrm{T}-700$, per la carretera que es dirigeix cap a Vimbodí i cap a Vilanova de Prades. Poc abans d'arribar a la cruïlla de carreteres, es trobarà un trencall per la dreta que es dirigeix cap el Tossal de la Baltasana. Caldrà agafar-lo i a uns $2 \mathrm{Km}$ de la carretera es trobaran unes antigues mines, per on farem una nova aturada, a uns 7'5 Km, des la parada anterior

En aquest recorregut, es passarà per uns afloraments de granits i de granodiorites (que es troben a la mateixa sortida de la població). Més endavant, es troben uns afloraments del Carbonífer, constituïts per esquits, quarsites i nivells calcosilicatats. Si s' ha passat pel Coll de Serafí, primer s'han trobat uns afloraments dels materials rogencs del Buntsandstein, i tot seguit uns granits i granodiorites, coberts parcialment pels anteriors.

Tot i així, en arribar al Tossal de la Baltasana, es troben uns afloraments dels granits i granodiorites, coberts parcialment pels materials del Buntsandstein. Entre els afloraments de les roques granítiques i granodiorítiques, es fa clarament palesa una mineralització filoniana, la qual afecta també als materials triàsics del Buntsandstein.

Sobre aquestes mineralitzacions s'han desenvolupat unes activitats mineres, encaminades a l'aprofitament de la BARITINA. Amb ella, també es troben altres minerals, com són els següents: PIROLUSITA (dendrítica), CALCITA i QUARS. 
En aquest indret va haver-hi una explotació minera, la qual es troba tapiada a I'actualitat. (fotografia 7).

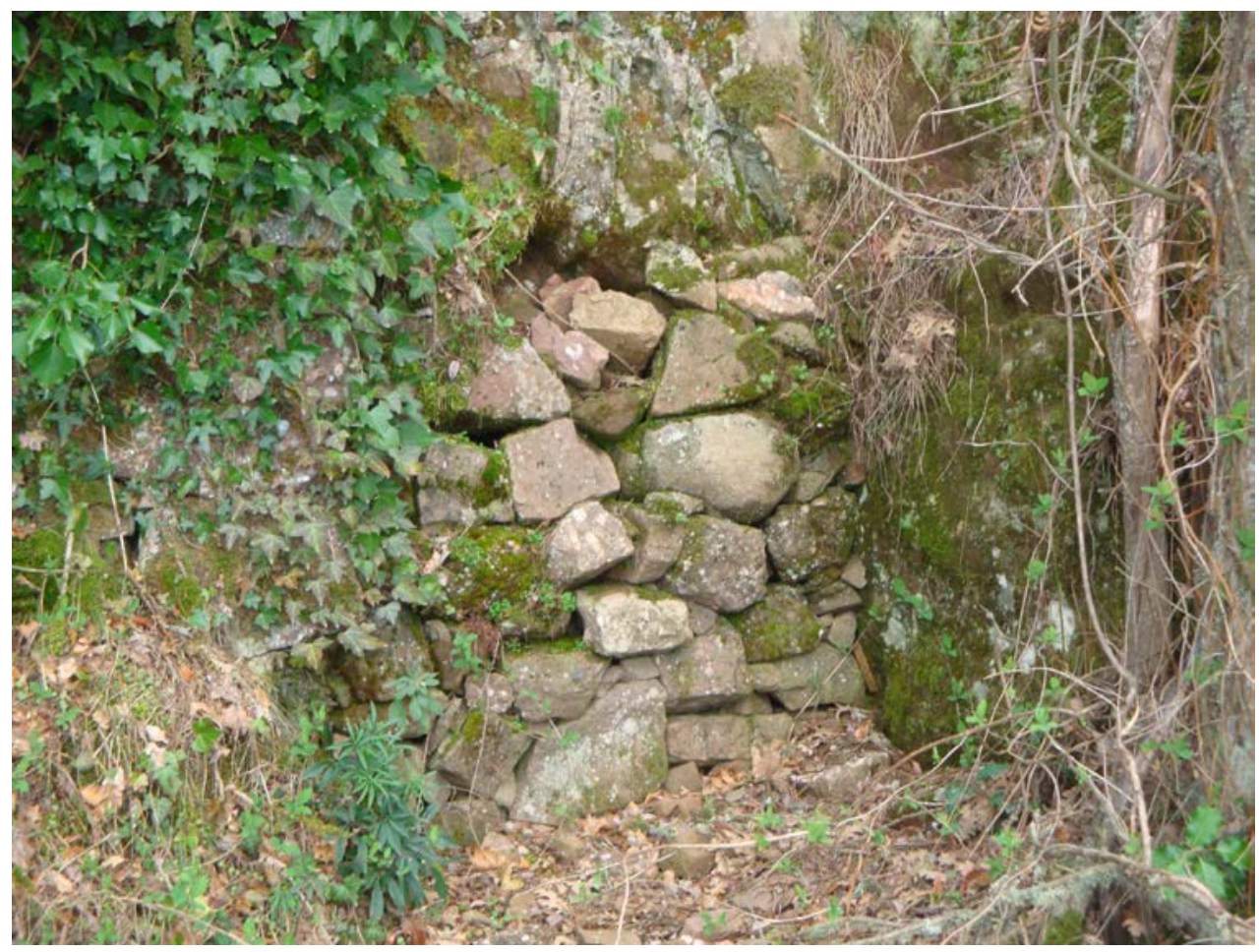

Fotografia 7. Antiga entrada a la mina, actualment tapada

En aquest indret finalitza el recorregut de l'itinerari 


\section{Bibliografia}

COLOMBO, F. (1986).- Estratigrafia y Sedimentologia del Paleógeno continental del borde meridional occidental de los Catalánides (provincia de Tarragona). Cuadernos de Geologia Ibérica, vol.10, pp.55-115. Madrid.

COLOMBO, F. (1989).- El Montsant; aspectes geològics (en "10 sortides per la Catalunya Sud"). 2on. Sympósium sobre l'Ensenyament de les Ciències Naturals, Tarragona. Edit. Eumo. pp.87-108. Barcelona.

GUIMERÀ, J. et altri /1992).- Geologia (II), Història Natural dels Països Catalans, Vol.2, 547 pag. Enciclopèdia Catalana, S,A, Barcelona.

IGME (1978a).- Mapa Geològic de España a escala 1:50.000 (2a Sèrie). Full i memòria $n^{\circ} \underline{445}$ (Cornudella del Montsant). Inst. Tecnol. GeoMinero España. Madrid.

IGME (1978b).- Mapa Geològic de España a escala 1:50.000 (2a Sèrie). Full i memòria $n^{\circ} \underline{472}$ (Reus). Inst. Tecnol. GeoMinero España. Madrid.

MATA-PERELLÓ, J.M. (1991).- Els Minerals de Catalunya. Institut d’Estudis Catalans. Arxius de la Secció de Ciències, T.XLVIII, 506 pag. Barcelona.

MATA-PERELLÓ, J.M. (1996).- Itinerari geològic i mineralògic per les comarques del Priorat i del Baix Camp: des de Reus a Cornudella del Montsant, per Prades. Inèdit, 12 pàgines. Manresa.

MATA-PERELLÓ, J.M. (1998).- Recerca geològica i mineralògica per les comarques del Baix Camp i del Priorat: des de les Borges del Camp a Prades; i del Coll d'Albarca a Cornudella de Montsant, Xaragall, sèrie $B, \mathrm{n}^{\circ}$ 100, 18 pag. Manresa.

MATA-PERELLÓ, J.M. (2004).- Recorregut de recerca geològica i mineralògica per les comarques del Baix Camp i del Priorat: des de Reus a I'Alforja, la Febró i Prades Inèdit, 10 pag. Manresa.

MATA-PERELLÓ, J.M. (2005).- Recorregut de recerca geològica i mineralògica per la comarca del Baix Camp: des de Pratdip a Mont-roig del Camp i des de les Borges del Camp a Prades. Inèdit. 12 pàgines. Manresa.

MATA-PERELLÓ, J.M. (2012).- Recorregut de recerca geològica i mineralògica per les comarques del Baix Camp i de la Conca de Barberà: des de Botarell i les Borges del camp a I'Alforja, la Febró, Prades i a Vilanova de Prades. Inèdit. 20 pàgines. Manresa.

MATA-PERELLÓ, J.M. i COLLDEFORNS, B. (1994).- Itinerari geològic i Mineralògic des d'Ulldemolins a les Borges del Camp. Inèdit, 12 pàgines. Manresa.

MELGAREJO,J.C. (1992).- Estudio geológico y metalogenético del paleozoico del sur de las Cordilleras Costeras Catalanas. Memórias dels Instituto Tecnológico y Geo-Minero de España, tomo 103, 605 pag. Madrid.

MELGAREJÓ, J.C. et altri (1993).- Mapa Metalogénico de España a escala 1:200.000. full i

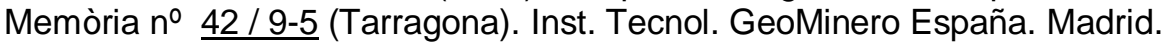

RIBA, O. et altri (1976).- Geografia Física dels Països Catalans. Edit. Ketres, 254 pàgines. Barcelona. 